\title{
MÉTODO DE INTERPOLAÇÃO COKRIGAGEM NA ESTIMATIVA DO DAP DA SERINGUEIRA
}

\author{
Marcelo Soares Altoé ${ }^{1}$ \\ João Marcelo Soares Pereira ${ }^{2}$ \\ Samuel de Assis Silva ${ }^{3}$ \\ Julião Soares de Souza Lima ${ }^{4}$
}

Resumo: Este trabalho foi realizado na cultura da seringueira avaliando o DAP (diâmetro a altura do peito) e DBT (diâmetro da base do tronco) das árvores (clone Fx 3864), coletados aos trinta e aos quarenta e dois meses após plantio das mudas. O objetivo foi estudar a variabilidade espacial destas variáveis e utilizar o DBT como covariável para estimar por cokrigagem o DAP nas duas medições. A seringueira foi plantada no espaçamento $3 \times 7 \mathrm{~m}$. Na área foi demarcada uma malha amostral com 200 plantas, sendo cada ponto amostral no espaçamento $6 \times 7 \mathrm{~m}$. Nas duas medições obteve-se o DAP1 de 4,40 cm, o DBT1 de 5,61 cm, o DAP2 de 5,38 cm e o DBT2 de 6,64 cm, respectivamente. As variáveis apresentaram forte grau de dependência espacial, com ajustes dos semivariogramas ao modelo exponencial aos trinta meses e o esférico aos quarenta e dois meses, apresentando o mesmo padrão de distribuição espacial em cada medição, com alcances variando de 9,0 a 12,0 m. Os mapas construídos por krigagem e cokrigagem apresentaram forte similaridade para as duas variáveis na área, em cada medição.

Palavras-chave: Semivariograma cruzado; Krigagem; Desenvolvimento inicial.

\footnotetext{
${ }^{1}$ Agronomia/Universidade Federal do Espírito Santo, Brasil. E-mail: marcelosoaresaltoe@hotmail.com.

2 Engenheiro Civil/Universidade Federal do Espírito Santo, Brasil. E-mail: jmsoarespereira@hotmsil.com.

3 Agronomia/Universidade Federal do Espirito Santo, Brasil. E-mail: samuel.assilva@gmail.com.

${ }^{4}$ Engenheiro Agrícola/Universidade Federal do Espirito Santo, Brasil. E-mail: limajss@yahoo.com.br.
} 